\title{
XPS and EDS Analysis of VC Coatings Prepared by TD Process
}

\author{
Kong Dejun ${ }^{1,2}$, Wang Jinchun ${ }^{1}, \quad$ Guo Haoyuan ${ }^{1}$ \\ ${ }^{1}$ Changzhou University, Changzhou 213164, China; ${ }^{2}$ Jiangsu Key Laboratory of Materials Surface Science and Technology, Changzhou \\ 213164, China
}

\begin{abstract}
VC (vanadium carbide) coating was prepared on the substrate surface of $\mathrm{Cr} 12 \mathrm{MoV}$ cold worked die steel by TD (thermal diffusion) process using anhydrous borate, FeV50, FeSi45 as main materials. The structures and the chemical element distributions of the coating were characterized with SEM (scanning electron microscope), XRD (X-ray diffraction), XPS (X-ray photoelectron spectroscopy) and EDS (energy dispersive spectrometer), respectively. The chemical element distributions of VC coating surface and interface were analyzed with plane scan of EDS, and the mechanism of interfacial metallurgical bonding was discussed. The results show that the $\mathrm{VC}$ coating is a compound, consisting of $\mathrm{C}$ and $\mathrm{V}$ elements, and the concentration of $\mathrm{V}$ atom is twice as large as that of $\mathrm{C}$ atom. The $\mathrm{VC}$ coating is single $\mathrm{VC}$ phase, where the electron binding energy of $\mathrm{V}$ element is located at $512.8 \mathrm{eV}$, and that of $\mathrm{C}$ element is located at $282.2 \mathrm{eV}$. The diffusion between $\mathrm{V}, \mathrm{C}$ and Fe elements occur at the coating interface and a layer of interface diffusion is formed, and the interface of VC coating-substrate is combined with the metallurgical bonding.
\end{abstract}

Key words: VC coating; TD (thermal diffusion) process; bonding interface

VC coating is one of the highest hardness transition metal carbon compounds and also a stoichiometrical compound ${ }^{[1,2]}$. It has a face-centred cubic structure with high melting point, high hardness and high chemical stability, etc. ${ }^{[3]}$ Therefore it is widely used in materials modification. There are many methods of preparing VC coating, such as direct carbonization, in situ burning form, and TD (thermal diffusion) processing ${ }^{[2-4]}$. VC coating can be formed in the mold surface by TD process, which is one of surface treatment methods of solving surface pulled damage of forming $\mathrm{die}^{[4]}$. At present, TD surface strengthening process is widely used for moulds in Japan, Korea and America. However, the researches on TD process are still at experimental stage, and used rarely in the actual production, which somewhat restrict the application of TD process in industries. The investigations about TD process mainly focused on growth mechanism, structure, abrasion performance of VC coating ${ }^{[5-8]}$. The related chemical element distributions in $\mathrm{VC}$ coating showed that $\mathrm{C}$ concentration had a slight increase in coating interface, while $\mathrm{C}$ content first slightly increased to the maximum capacity, presenting a decreasing trend ${ }^{[9]}$. But there was little report about the chemical element plane distributions of VC coating interface and metallurgical bonding formed by interface diffusion. In the present investigation the VC coating was prepared on the $\mathrm{Cr} 12 \mathrm{MoV}$ cold worked die surface by TD process. The structures and the chemical element distributions were analyzed with SEM, EDS, XRD and XPS, respectively, and the metallurgical bonding mechanism of the coating interface was analyzed to provide the basic experiments for actual applications.

\section{Experiment}

The substrate material was $\mathrm{Cr} 12 \mathrm{MoV}$ steel, and the equipment was a TD salt bath furnace with the highest heating temperature of $1300{ }^{\circ} \mathrm{C}$ and automatic control

\footnotetext{
Received date: January 19, 2015

Foundation item: The Science and Technology Support Project of Jiangsu Province, China (BE2014818)

Corresponding author: Kong Dejun, Ph. D., Professor, College of Mechanical Engineering, Changzhou University, Changzhou 213164, P. R. China, Tel 0086-519-83290205, E-mail: kong-dejun@163.com

Copyright (C) 2016, Northwest Institute for Nonferrous Metal Research. Published by Elsevier BV. All rights reserved.
} 
temperature accuracy of $\pm 5{ }^{\circ} \mathrm{C}$. The raw materials were composed of the following powders: (1) no-water borax salt, the particle morphology is shown in Fig.1a, and the average size was 20 30 $\mu \mathrm{m}$; (2) reducing agent FeSi45, its particle morphology is shown in Fig.1b, and the average size was 10 15 $\mu \mathrm{m}$; (3) vanadium agent FeV50, its particle morphology is shown in Fig.1c, and the average size was $20 \sim 25 \mu \mathrm{m}$. The XRD patterns of raw materials are shown in Fig.2.

When the salt bath was prepared, first of all, the salt furnace was started by base salt. Then the vanadium agent of FeV50 and reducing agent of FeSi45 were mixed evenly into salt bath, and finally the activator of $\mathrm{NaF}$ was put in to increase the liquidity of salt bath. After full melting, Cr12MoV cold worked die steel was soaked in salt bath at the temperature of $1200{ }^{\circ} \mathrm{C}$ for $12 \mathrm{~h}$, afterward quenched in oil at the tempering of $180{ }^{\circ} \mathrm{C}$ for $2 \mathrm{~h}$, and then the required sample was obtained. The surface-interface morphologies and chemical element distributions were observed and tested with JSM-6360 LA typed SEM and the electronic energy equipment. The phase of VC coating and the XPS map were analyzed by D/max2500PC type XRD and ESCALA 250 type XPS, respectively.

\section{Analysis of Experimental Results}

\subsection{Surface morphology, EDS and XRD analysis}

The coating surface is smooth and dense, as shown in Fig.3a. The distribution of grain and particle size is uniform with certain porosity. EDS analysis of the surface is shown in Fig.3b.
The coating is composed of $\mathrm{V}$ and $\mathrm{C}$ elements without other impurities, and the mass fraction is $\mathrm{V}=89.45 \%, \mathrm{C}=10.55 \%$, and the atomic fraction is $\mathrm{V}=66.66 \%, \mathrm{C}=33.34 \%$, which is the main reasons for that $\mathrm{VC}$ coating has a high hardness. The microhardnesses of coating surface and substrate surface are 30500 32000 MPa and 5000 5500 MPa under the loading of $2 \mathrm{~N}$ for $15 \mathrm{~s}$, respectively, measured by HXD-1000 type micro hardness tester, forming the function hardness gradient that improved effectively the surface resistance strain capacity and the surface quality of forming die.

The phase structure was analyzed with $\mathrm{D} / \max 2500 \mathrm{PC}$ type X-ray diffraction, the test parameters were: $\mathrm{Cu}$ target $\mathrm{K} \alpha$ radiation $(\lambda=0.15418 \mathrm{~nm})$, pipe voltage of $40 \mathrm{kV}$, current of $100 \mathrm{~mA}$. The results are shown in Fig.4, and there is single $\mathrm{VC}$ phase with a little amount of $\mathrm{V}_{8} \mathrm{C}_{7}$ and $\mathrm{C}$ atoms, no brittle $\alpha-\mathrm{FeV}$ phase, which is the same result as energy spectrum analysis.

\subsection{XPS analysis of the surface}

XPS energy spectrum analysis was conducted with Thermo ESCALAB 250 type X-ray photoelectron spectroscopy instrument. The test parameters were: monochrome Al $\mathrm{K} \alpha(h v=1486.6 \mathrm{eV})$, power of $150 \mathrm{~W}$, $\mathrm{X}$-ray beam spot of $500 \mu \mathrm{m}$, and fixing through analyzed energy of $30 \mathrm{eV}$. The surface elements of XPS full spectrum are shown in Fig.5a, where V 3p, V 3s, C 1s, V 2p and V 2s signals are detected. The existence form of the surface elements shows that the surface is mainly composed of $\mathrm{V}$ and $\mathrm{C}$, which is the same as the EDS result.

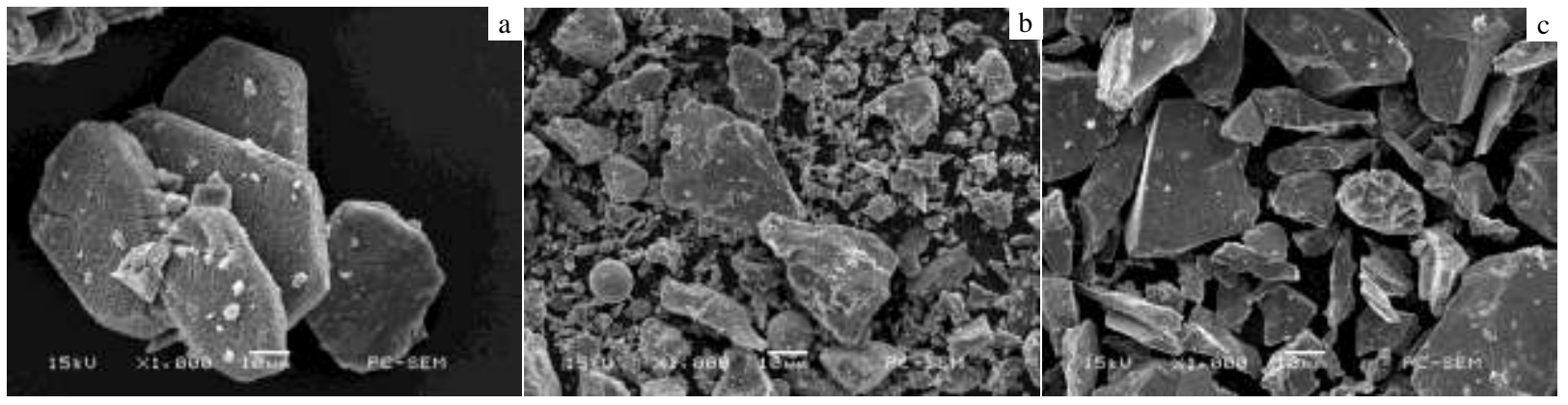

Fig.1 Surface morphologies of the salt raw materials: (a) borax, (b) silicon iron powder, and (c) vanadium iron powder
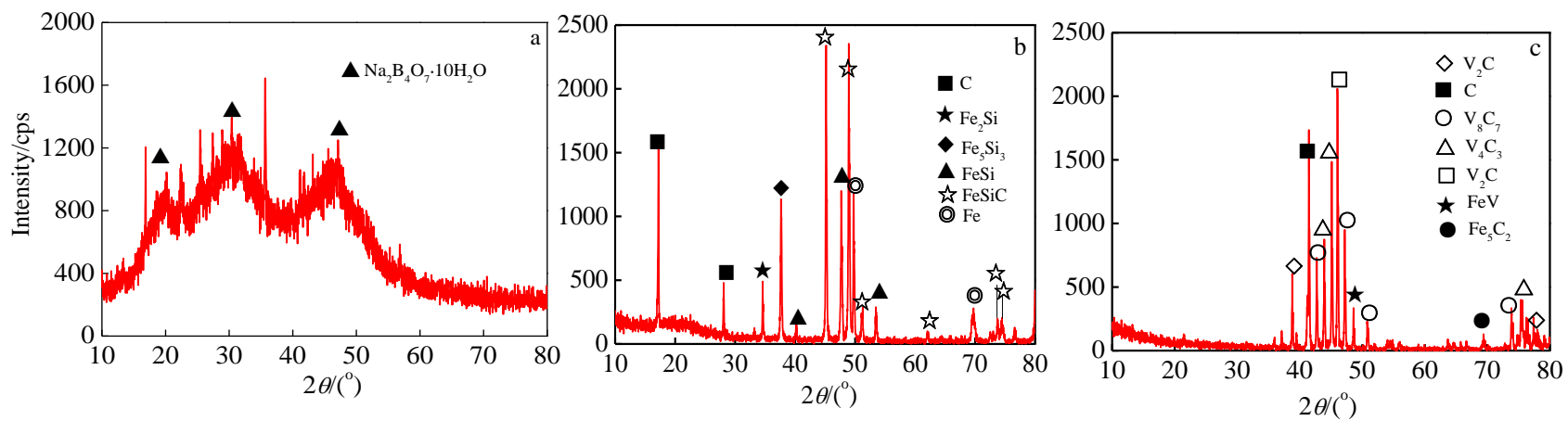

Fig.2 XRD patterns of the raw materials: (a) borax, (b) silicon iron powder, and (c) vanadium iron powder 


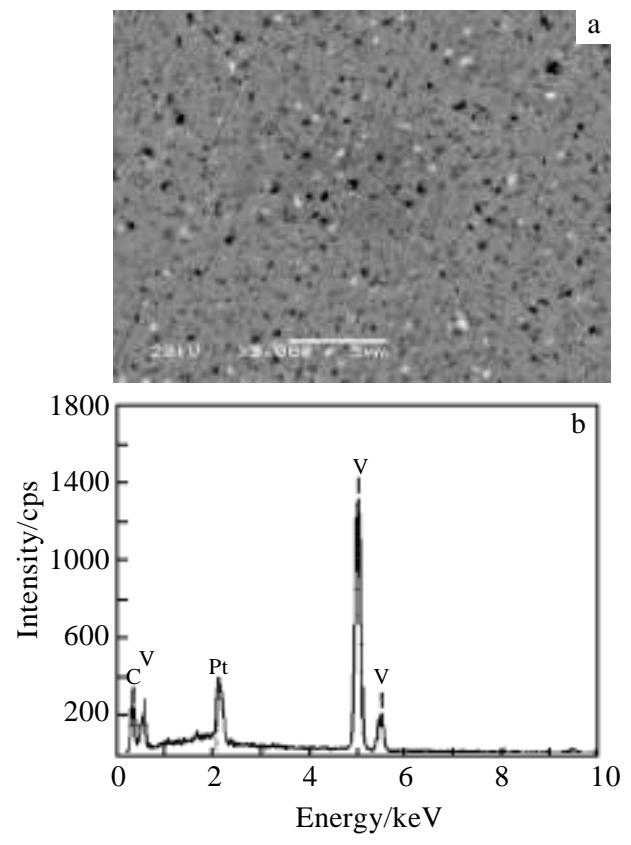

Fig.3 Surface morphology (a) and EDS analysis (b) of VC coating

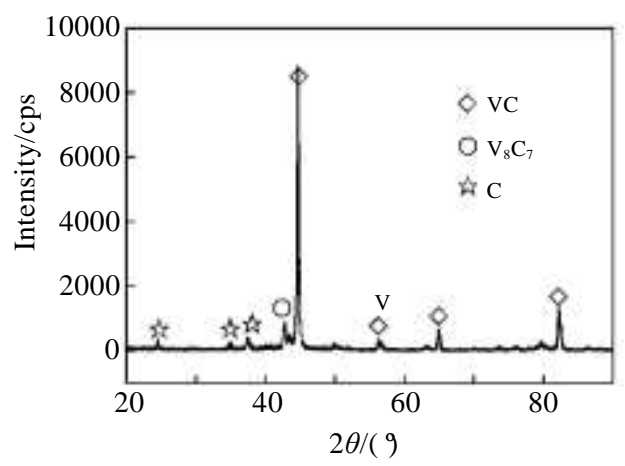

Fig.4 XRD analysis of VC coating

The electron binding energy of $\mathrm{V}$ is $512.8 \mathrm{eV}$ (Fig.5b), $\mathrm{V} 2$ p3/2 peak appears in $512.8 \mathrm{eV}$, and the full width at half maximum (FWHM) is $1.6 \mathrm{eV}$. Besides, another $520.4 \mathrm{eV}$ also appears in $\mathrm{V} 2_{\mathrm{p} 1 / 2}$ peak place, corresponding to $\mathrm{V}^{4+}$ and $\mathrm{V}^{5+}$. Element $\mathrm{V}$ comes from the salt bath furnace $\mathrm{FeV}$, and the wide cavitation phenomenon of $\mathrm{V}$ core level does not happen obviously ${ }^{[10]}$. C 1s peak appears in 282.2, 283.31 and $285.12 \mathrm{eV}$ (Fig.5c), and the full widths at half maximum (FWHM) are 0.82, 1.62 and $1.44 \mathrm{eV}$, respectively, while the peak of $282.2 \mathrm{eV}$ is $\mathrm{C}$, coming from the $\mathrm{Cr} 12 \mathrm{MoV}$ whose $\mathrm{C}$ content is $1.45 \% \sim 1.70 \%$ with mass fraction corresponding to the VC coating in Ref[11], and there is no other element, showing the coating is made of $\mathrm{V}$ and $\mathrm{C}$ whose existence form is $\mathrm{VC}$, not the forming of clearance atoms with $\mathrm{V}$ solid solution.

\subsection{Plane scans of the surface}

The plane scans of $\mathrm{V}$ and $\mathrm{C}$ are shown in Fig.6a and $6 \mathrm{~b}$, The surface is rich in $\mathrm{V}$ and $\mathrm{C}$. Because the lattice constant of $\mathrm{VC}$ coating is $0.4160 \mathrm{~nm}$, while that of $\mathrm{Cr} 12 \mathrm{MoV}$ is 0.35 $797 \mathrm{~nm}$, there is a relatively small difference and good compatibility. Therefore, during the diffusion process it is easy to grow through combination attachment, forming the VC carbide structure. The result of plane scan is shown in Fig.6c, and the atomic fraction is $\mathrm{V} 35.52$ as well as $\mathrm{C}$ 64.48 , where the content of $\mathrm{C}$ is about twice as large as that of $\mathrm{V}$ element. The composition of the coating is uniform and there are no sudden element changes. Combining with Fig.3a, it can be seen that $\mathrm{V}$ and $\mathrm{C}$ are mainly distributed with the particles in Fig.6a and 6b, which ensures that VC compound is composed of $\mathrm{V}$ and $\mathrm{C}$ particles.

\subsection{Plane scans of the interface}

The coating is rich in $\mathrm{V}$ while the substrate is rich in $\mathrm{Fe}$, which leads to the formation of diffused layer near the bonding interface. Therefore, the metallurgical bonding is realized. The different elements play different roles in the transition layer of interface. In this system, the activity of chemical elements is: $\mathrm{C}>\mathrm{Si}>\mathrm{V}>\mathrm{Cr}>\mathrm{Fe}>\mathrm{Mo}$. In the salt bath, the replacement reaction of $\mathrm{V}$ in salt bath with $\mathrm{C}$ occurs, the $\mathrm{C}$ in the substrate diffuses to the substrate surface, and it reacts with $\mathrm{V}$ atoms in salt at $770{ }^{\circ} \mathrm{C}$ to form $\mathrm{VC}$, and $\mathrm{FeV}+\mathrm{C}=\mathrm{VC}+\alpha-\mathrm{Fe}^{[3]}$. When the temperature is up to $1200{ }^{\circ} \mathrm{C}$, the rest $\mathrm{V}$ will continue to finish the unfinished carbonization reaction, the solid solution $\mathrm{VC}$ is formed from VC, and its grain is bulky. From Table 1, it can be seen that $\mathrm{Fe}$ has certain diffusion ability because of its
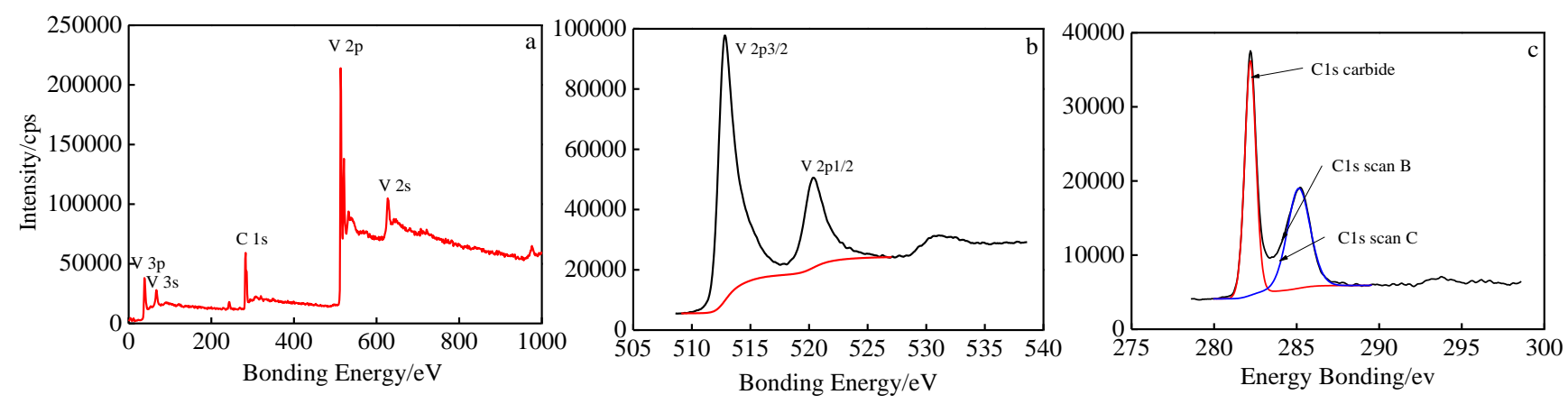

Fig.5 XPS spectra of VC coating surface: (a) full spectrum, (b) spectrum of V element, and (c) spectrum of C element 

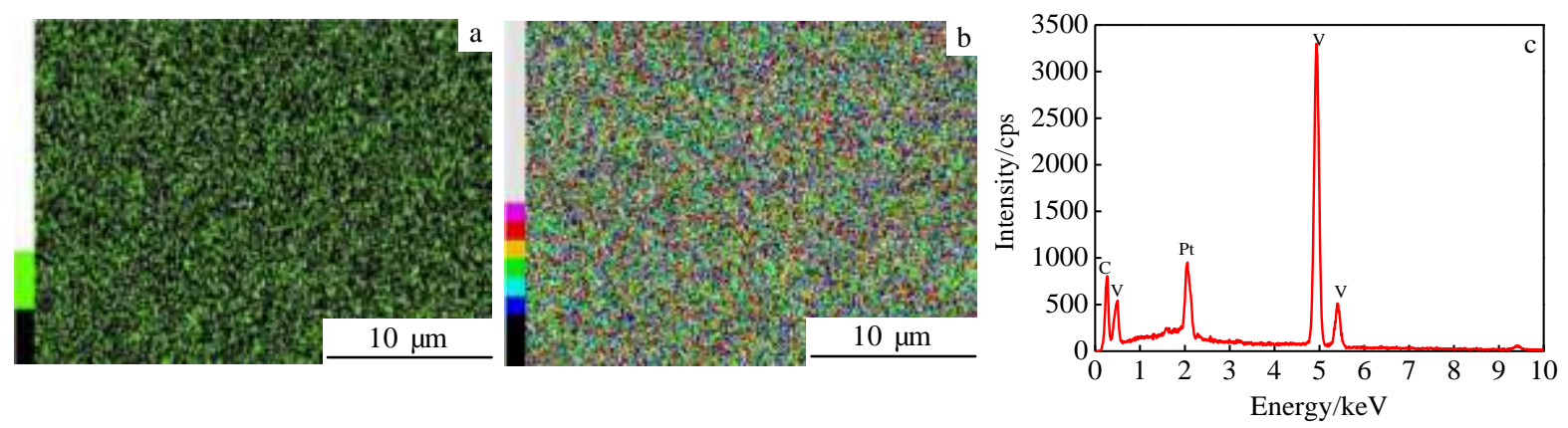

Fig.6 Plane scans of VC coating surface C (a), V (b), and EDS spectrum (c)

smaller atomic radius, and a metallurgical bonding is formed in interface diffusion layer ${ }^{[12]}$. As the chemical activity of $\mathrm{V}$ is greater than that of $\mathrm{Fe}$, the diffusion of $\mathrm{Fe}$ in $\mathrm{VC}$ is limited, at the same time, the radius of $\mathrm{C}$ atom is much smaller than that of $\mathrm{V}$, which makes $\mathrm{C}$ atom successfully diffuse to the coating, and it is the source of the generation element. The radii of $\mathrm{Cr}$, Mo and $\mathrm{Si}$ atoms are exactly the same as that of $\mathrm{V}$ atom, because its diffusion coefficient is small, and it is difficult to diffuse in the coating. Therefore, in the interface of $\mathrm{VC}$ there exists mainly the diffusion among $\mathrm{C}, \mathrm{V}$ and $\mathrm{Fe}$, which is the main mechanism of forming metallurgical bonding at $\mathrm{VC}$ coating interface.

During the thermal diffusion, the mutual diffusion between $\mathrm{V}$ and $\mathrm{C}$ happens, and $\mathrm{VC}$ coating is formed in the substrate surface. Fig.7a shows the morphology of VC coating interface with the thickness of about $5 \mu \mathrm{m}$, whose density and continuity are very well to form a completely covered layer. The diffusion between the coating and the substrate is significant, indicating that the coating interface is metallurgical combination mode. The plane scans of energy spectrum are shown in Figs.7b and 7c. In the VC coating, $\mathrm{V}$ and $\mathrm{C}$ are uniformly distributed, and mainly concentrated on the coating, and some $\mathrm{V}$ in the coating spread to the substrate side in the interface diffusion layer. $\mathrm{Fe}$ in the substrate diffuses to the interface diffusion layer. The solid-phase reaction is increased significantly when the temperature is up to $870^{\circ} \mathrm{C}$ and $\mathrm{Cr}$ in the interface begins to diffuse and a reaction takes place in interface ${ }^{[13]}$. As it is fully spread to present the continuous distribution pattern in the interface and promote the gradient distribution of chemical composition, a gradient change of structure and performance occurs ${ }^{[14]}$. Cr is uniformly distributed near the interface, which is beneficial to realize the metallurgical bonding. In the process of diffusion, $\mathrm{Cr}$ is body centered

Table 1 Atom radii and coefficients of thermal expansion

\begin{tabular}{ccc}
\hline Chemical elements & $\begin{array}{c}\text { Atom } \\
\text { radius/nm }\end{array}$ & $\begin{array}{c}\text { Coefficients of thermal } \\
\text { diffusion }\end{array}$ \\
\hline $\mathrm{Fe}$ & 0.126 & 11.8 \\
$\mathrm{~V}$ & 0.192 & 8.4 \\
$\mathrm{C}$ & 0.077 & 7.1 \\
$\mathrm{Cr}$ & 0.185 & 4.9 \\
$\mathrm{Mo}$ & 0.201 & 4.8 \\
$\mathrm{Si}$ & 0.117 & 2.6 \\
\hline
\end{tabular}

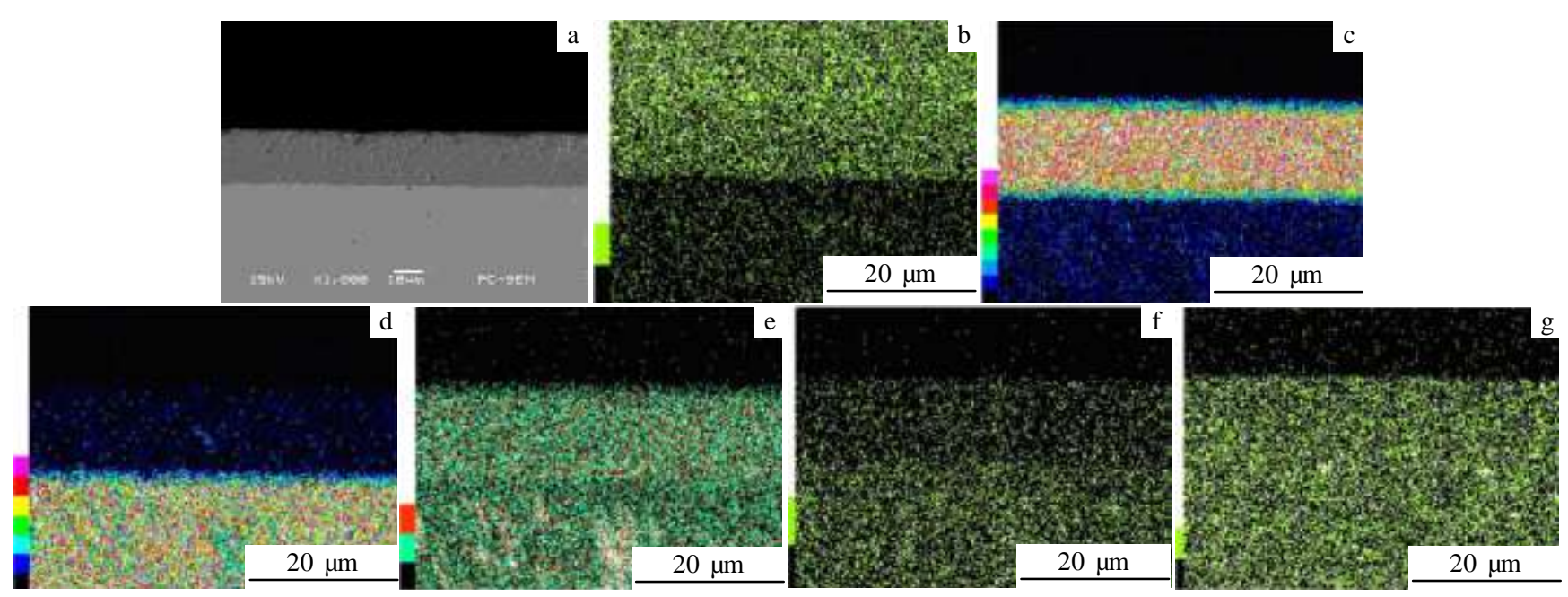

Fig.7 morphology of VC coating interface (a), and EDS plane scans of VC coating interface: (b) C, (c) V, (d) Fe, (e) Cr, (f) Mo, and (g) Si 


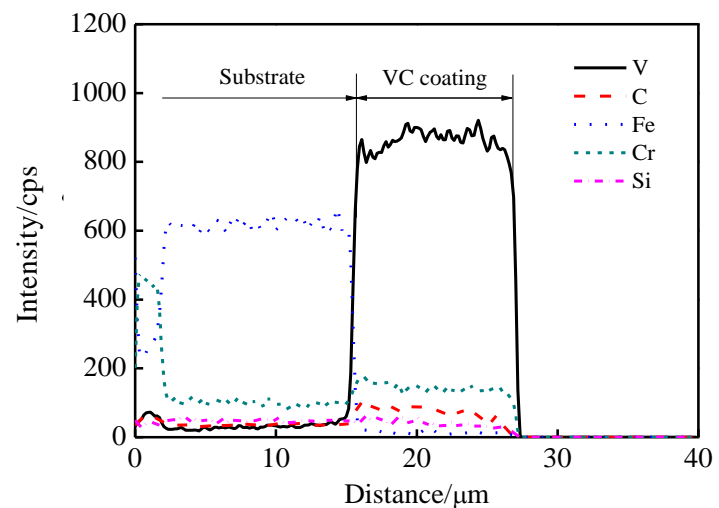

Fig. 8 Line scans of VC coating interface

cubic dot matrix and hard to form the substitutional solid solution with $\mathrm{Fe}$, and it is relatively difficult to diffuse in the substrate ${ }^{[15]}$. $\mathrm{Fe}$ and $\mathrm{Cr}$ have an obvious boundary, shown in Figs.7d and 7e. $\mathrm{V}$ and $\mathrm{Fe}$ atoms in the interface change sharply and smoothly between the coating and the substrate. In the interface layer, $\mathrm{V}$ and $\mathrm{Fe}$ generate $\mathrm{Fe}-\mathrm{V}$ intermetallic. From Fe-V phase diagram ${ }^{[16]}$, it is known that $\mathrm{FeV}$ would dissolve in $\alpha$-Fe at about $1373 \mathrm{~K}$, forming the interstitial solid solution $(\alpha-\mathrm{Fe}, \mathrm{V})^{[17]}$. The $\mathrm{Mo}$ and $\mathrm{Si}$ atoms in the substrate are mainly distributed in the substrate which are out of the coating, Mo and $\mathrm{Si}$ almost do not diffuse relatively to the $\mathrm{V}$ atoms in coating, as shown in Fig. $7 \mathrm{f}$ and $7 \mathrm{~g}$, and there is no apparent diffusion.

\subsection{Line scan of the interface}

As shown in Fig.8, $\mathrm{V}$ is concentrated in one side of interface and $\mathrm{V}$ content presents a continuous belt gradient distribution in coating interface diffusion layer while it is evenly distributed both in the coating and in the substrate. The contents of $\mathrm{V}$ and $\mathrm{Fe}$ change greatly in the bonding interface, while $\mathrm{V}$ and $\mathrm{C}$ form $\mathrm{VC}$ phase. $\mathrm{Fe}$ is riched in the substrate, the diffusion layer of interface appears corresponding concentration gradient step, while the other elements have the more even distributions.

\section{Conclusions}

1) VC coating prepared by TD process is composed of $\mathrm{V}$ and $\mathrm{C}$ which is a single $\mathrm{VC}$ phase, and the surface microhardness reaches 30500 32000 MPa.

2) $\mathrm{V}$ atomic electrons energy is $512.8 \mathrm{eV}$, exists in $\mathrm{V}^{4+}$ and $\mathrm{V}^{5+}$, while $\mathrm{C}$ atomic electrons energy is $282.2 \mathrm{eV}$, without any other element existence.
3) VC coating interface is an interface diffusion layer formed by mutual diffusion among $\mathrm{V}, \mathrm{C}$ and $\mathrm{Fe}$, which is the main mechanism of metallurgical combination at $\mathrm{VC}$ coating interface.

\section{References}

1 Li Guangze, Wu Xiaoyan, Chen Yanghui et al. Chinese Journal of Vacuum Science and Technology [J], 2009, 29: 168 (in Chinese)

2 Wu Enxi, Yan Lianwu, Hu Maozhong. Cemented Carbide [J], 2004, 21: 1

3 Gong Wei, Wang Yisan, Wang Jing et al. Transactions of Materials and Heat Treatment [J], 2008, 29: 3 (in Chinese)

4 Kong Dejun, Zhou Chaozheng. Journal of China University of Mining \& Technology [J], 2011, 40 (1): 162 (in Chinese)

5 Liu Xiujuan, Wang Huachang, Li Weidong et al. Transactions of Materials and Heat Treatment [J], 2006, 27: 119 (in Chinese)

6 Liang Lianke. Iron Steel Vanadium Titanium [J], 1999, 20: 43 (in Chinese)

7 Sun Rongyao, Hao Shiming. Journal of Northeast University of Technology [J], 1991, 12: 173 (in Chinese)

8 Aghaie-Khafri M, Fazlalipour F. Journal of Physics and Chemistry of Solids [J], 2008, 69: 2465

9 Liu Xiujuan, Wang Huachang. Transactions of Materials and Heat Treatment [J], 2008, 29 (5): 165 (in Chinese)

10 Hyun I Kim, Peter Frantz, Stephen V Didziulis et al. Surface Science [J], 2003, 543: 103

11 Jinwen Ye, Ying Liu, Zhiwei Zhao et al. Journal of Alloys and Compounds [J], 2010, 496: 278

12 Li Jia, Xia Changqing, Gu Yi et al. The Chinese Journal of Nonferrous Metals[J], 2004, 14: 1889 (in Chinese)

13 Peng Xiaomin, Xia Changqing, Sun Zhenqi. Mining and Metallurgical Engineering [J], 2005, 26: 84

14 Tong Jianguo, Gao Xiaodan, Qu Haitao et al. Journal of University of Science and Technology Beijing [J], 2009, 31: 451 (in Chinese)

15 Liu Guoxun. Physical Metallurgy Principle[M]. Beijing: Metallurgical Industry Press, 1996 (in Chinese)

16 Henfrey A W, Fender B E F. Acta Crystallogr B [J], 1970, 26 : 1882

17 Ding Yichao, Wang Yisan, Wang Jing et al. Journal of Sichuan University, Engineering Science Edition[J], 2007, 39: 113 (in Chinese) 


\title{
TD 处理制备的 VC 涂层 XPS 谱与 EDS 面扫描分析
}

\author{
孔德军 ${ }^{1,2}$, 王进春 ${ }^{1}$, 郭皓元 ${ }^{1}$ \\ (1. 常州大学, 常州 213164)
}

(2. 江苏省材料表面科学与技术重点实验室, 常州 213164)

\begin{abstract}
摘 要: 以无水硼砂、 $\mathrm{FeV} 50$ 和FeSi45 为主要原料, 通过 $\mathrm{TD}$ 和扩散处理在 $\mathrm{Cr} 12 \mathrm{MoV}$ 基体表面制备了 VC涂层。利用扫描电镜(SEM)、X射 线衍射(XRD)、X射线光电子能谱(XPS)和能谱分析(EDS)等手段对 $\mathrm{VC}$ 的组织结构和化学元素分布进行了表征。用能谱面扫描分析了 $\mathrm{VC}$ 涂层表面和界面化学元素分布, 对其界面冶金结合机理进行了探讨。结果表明, VC涂层为C和V两元素组成的化合物, 其中 V原子浓度 大约是 $C$ 原子的 2 倍; $V C$ 涂层为单一的 $V C$ 相, $V$ 元素电子结合能位于 $512.8 \mathrm{eV}, \mathrm{C}$ 元素电子结合能位于 $282.2 \mathrm{eV} ; \mathrm{V} 、 \mathrm{C}$ 和 $\mathrm{Fe}$ 等元素在涂层 界面处发生了相互扩散，形成了界面扩散层，涂层-基体结合界面为治金结合方式。
\end{abstract}

关键词: VC 涂层; TD 处理; 结合界面

作者简介: 孔德军, 男, 1966年生, 博士, 教授, 常州大学机械工程学院, 江苏 常州 213164, 电话: 0519-83290205, E-mail: kong-dejun@163.com 